\title{
ALELOPATIA DO EXTRATO AQUOSO DE FOLHAS DE AROEIRA NA GERMINAÇÃO DE SEMENTES DE ALFACE
}

\author{
Clarice Sales Moraes de Souza \\ Aluna concluite de Agronomia UFERSA - Dpt $^{\circ}$ de Ciências Vegetais - Laboratório de Análise de Sementes - \\ E-mail: clarice_agro@hotmail.com; \\ Weydson Luiz Pedrosa da Silva \\ Aluno concluite de Agronomia UFERSA - $\mathrm{Dpt}^{\circ}$ de Ciências Vegetais - Laboratório de Análise de Sementes - \\ E-mail: clarice_agro@hotmail.com; \\ Antonia Mirian Nogueira de Moura Guerra \\ Aluna de Graduação em Agronomia da UFERSA, Bolsista de Iniciação Científica - CNPq, Mossoró - RN \\ E-mail: mirianagronoma@hotmail.com; \\ Maria Clarete Ribeiro Cardoso \\ D. Sc. Professora da UFERSA - $\mathrm{Dpt}^{\circ}$ de Ciências Vegetais Professora Associada - \\ E-mail: clarete@ufersa.edu.br \\ Salvador Barros Torres \\ D. Sc. Pesquisador/Prof. EMPARN- UFERSA, Departamento de Ciências Vegetais de Tecnologia de Sementes - \\ E-mail: sbtorres@ufersa.edu.br
}

\begin{abstract}
RESUMO - O presente trabalho teve por objetivo avaliar a influência do extrato aquoso de folhas de aroeira (Schinus terebinthifolius Raddi) na germinação e desenvolvimento de alface. Os experimentos foram conduzidos no Laboratório de Análise de Sementes do Departamento de Ciências Vegetais da Universidade Federal Rural do Semi-Árido-UFERSA, em Mossoró-RN, no mês de novembro de 2007. O delineamento estatístico utilizado foi o inteiramente casualizado, em esquema fatorial (3x2), sendo o primeiro fator três concentrações de extrato aquoso de aroeira $(0,50$ e $100 \%)$ e duas condições (fervido e não fervido), com quatro repetições de 25 sementes por tratamento. Os dados obtidos foram submetidos a Analise de variância (Teste F) e os tratamentos comparados através do teste de Tukey, ao nível de 5\% de probabilidade pelo programa SISVAR - UFLA. As características avaliadas foram: primeira contagem, porcentagem de germinação, índice de velocidade de germinação. A porcentagem de germinação em extrato aquoso fervido e não fervido, apresentou diferença significativa nas três concentrações $0,50,100 \%$. Na porcentagem de germinação, a maior concentração $(100 \%)$ de extrato aquoso fervido e não fervido de aroeira ocorreu um menor numero de plântulas de alface, ocorrendo de mesmo modo para o IVG. O extrato aquoso de aroeira na concentração $(100 \%)$ apresentou efeito alelopático na germinação de sementes de alface.
\end{abstract}

Palavras-chave: Schinus terebinthifolius Raddi, efeito alelopático, desenvolvimento.

\section{ALLOPATHIC OF THE AQUEOUS EXTRACT OF AROEIRA LEAVES IN THE GERMINATION OF LETTUCE SEEDS}

\begin{abstract}
The present work had for objective to evaluate the influence of the aqueous extract of aroeira leaves (Schinus terebinthifolius Raddi) in the germination and lettuce development. . The experiments were led at the Laboratory of Analysis of Seeds of the Department of Vegetable Sciences of the Rural Federal University of the Semi-arid-UFERSA, in Mossoró$\mathrm{RN}$, in the month of November of 2007. The used statistical delineamento was it entirely actualized, in factorial outline $(3 \times 2)$, being the first factor three concentrations of aqueous extract of aroeira (0,50 and 100\%) and two conditions (boiled and not boiled), with four repetitions of 25 seeds for treatment. The obtained data were submitted her it Analyzes of variance (it Tests F) and the treatments compared through the test of Tukey, at the level of $5 \%$ of probability for the program SISVAR-UFLA. The appraised characteristics were: first count, germination percentage, index of germination speed. The germination percentage in boiled aqueous extract and not boiled, it presented significant difference in the three concentrations $0,50,100 \%$. In the germination percentage, the largest concentration $(100 \%)$ of boiled and not boiled aqueous extract of aroeira it happened a smaller one I number of lettuce plantlets, happening in a same way for IVG. The aqueous extract of aroeira in the concentration (100\%) it presented effect allopathic in the germination of lettuce seeds
\end{abstract}

Keywords: Schinus terebinthifolius Raddi, effect alelopático, development. 


\section{REVISTA VERDE DE AGROECOLOGIA E DESENVOLVIMENTO SUSTENTÁVEL GRUPO VERDE DE AGRICULTURA ALTERNATIVA (GVAA)}

\section{INTRODUÇÃO}

A alelopatia pode ser definida como a interferência positiva ou negativa de compostos metabólicos secundários produzidos por uma planta (aleloquímicos) e lançados no meio. Esta interferência sobre o desenvolvimento de outra planta pode ser indireta, por meio de transformação destas substâncias no solo pela atividade de microorganismos (FERREIRA e BORGHETTI, 2004). Então, além de interferir no desenvolvimento da planta, ocorre alteração no padrão e na densidade, sendo um fenômeno comum que ocorre largamente em comunidades de plantas, afirma Smith (1989).

Severino (2007) conduz que a alelopatia não vem a ser uma competição, pois não ocorre uma disputa de recursos limitados como luz, água e nutrientes, e sim na alelopatia trata-se de um efeito tóxico de substâncias produzidas por outras plantas. A alelopatia pode ser uma estratégia ecológica de competição, pois através desse mecanismo, uma planta pode interferir no crescimento da outra, reconhecida como um importante mecanismo ecológico que influencia a dominância vegetal, a sucessão, a formação de comunidades vegetais e de vegetação clímax, bem como a produtividade e manejo de culturas.

De acordo com Mano (2006) o termo "alelopatia" foi criado em 1937, pelo pesquisador alemão Hans Molisch, com a reunião das palavras gregas "allélon" e "pathos", que significam respectivamente, mútuos e prejuízo.

Os compostos alelopáticos liberados por uma planta poderão afetar o crescimento, prejudicar o desenvolvimento normal e até mesmo inibir a germinação das sementes de outras espécies vegetais (SILVA, 1978).

Para avaliar se uma planta possui alelopatia, Mano (2006) afirma que uma das principais variáveis analisadas é a germinação. Os testes de germinação são simples de serem realizados, no entanto há uma série de cuidados que devem ser tomados para que se possa ter respostas reproduzíveis. A temperatura, o substrato e a umidade influem bastante sobre a germinação e por isso devem ser controlados. As sementes teste devem ser de espécies cultivadas de boa qualidade, como tomate e alface, pois são facilmente encontradas e bastante sensíveis a vários aleloquímicos.

A aroeira brasileira, aroeira - vermelha ou aroeira mansa, como é popularmente conhecida. Pertencente a família Anacardiaceae, a Schinus terebinthifolius Raddi, ocorre em diversas vegetações, é amplamente disseminada, apresentando boa regeneração natural (NESELLO, 2006). De acordo com, Sigrist (2007) a aroeira é rica no seguinte óleo essencial: em mono e sesquiterpenos, em teor de $1 \%$ para as folhas e $5 \%$ para os frutos.

A alface é uma planta herbácea, muito delicada, com caule diminuto não ramificado. As folhas são muito grandes, lisas ou crespas, fechando-se ou não na forma de "cabeça", estando presas ao caule (FIGUEIRA, 1982).
A principal vantagem do uso de Lactuca sativa como alvo nos estudos alelopáticos reside na sensibilidade da espécie, mesmo em baixas concentrações de aleloquímicos. Além disso, a espécie apresenta outras peculiaridades que favorecem sua utilização: germinação rápida, em aproximadamente $24 \mathrm{~h}$; crescimento linear insensível às diferenças de $\mathrm{pH}$ em ampla faixa de variação e insensibilidade aos potenciais osmóticos (SOUZA, 2005).

Visto a importância do estudo de plantas com possíveis efeitos alelopáticos é justificado pela necessidade do desenvolvimento de uma agricultura sustentável. O objetivo deste trabalho foi avaliar a influência do extrato aquoso de folhas de aroeira (Schinus terebinthifolius Raddi) na germinação e desenvolvimento de alface, em condições de laboratório.

\section{MATERIAL E METODOS}

\section{Local e data dos experimentos}

Os experimentos foram conduzidos no Laboratório de Análise de Sementes, Departamento de Ciências Vegetais da Universidade Federal Rural do SemiÁrido-ufersa UFERSA, em Mossoró-RN, no mês de novembro de 2007.

\section{Materiais biológicos}

Para a realização dos experimentos foram utilizadas folhas de aroeira coletadas no Horto de Plantas Medicinais da UFERSA na cidade de Mossoró-RN. As sementes de alface, variedade Mônica SF 31 foram adquiridas em pontos comercias locais.

\section{Preparo de soluções}

As folhas da parte aérea de aroeira foram retiradas da planta, trituradas em liquidificador, $100 \mathrm{~g}$ de folha em $1 \mathrm{~L}$ de água destilada, onde $0,5 \mathrm{~L}$ foram fervidos e $0,5 \mathrm{~L}$ não fervido. . Em seguida armazenado em recipiente de vidro em temperatura ambiente durante 12 horas (período de descanso), para posterior utilização.

Após o período de descanso das soluções, estas foram filtradas com peneira e imediatamente utilizadas no experimento.

A partir da solução $(100 \mathrm{mg} / \mathrm{ml})$, de cada tratamento, foram realizadas as diluições_para as concentrações de 50 e $100 \mathrm{mg} / \mathrm{ml}$, totalizando três tratamentos, além do controle (zero $\mathrm{mg} / \mathrm{ml}$, água destilada).

\section{Tratamentos}




\section{REVISTA VERDE DE AGROECOLOGIA E DESENVOLVIMENTO SUSTENTÁVEL GRUPO VERDE DE AGRICULTURA ALTERNATIVA (GVAA)}

Para a avaliação da inibição da germinação de sementes e do desenvolvimento das plântulas de alface, dois discos de papel de filtro foram postos em placas de Petri, sendo em seguida, embebidos, com oito $\mathrm{mL}$ de solução dos extratos ( 50 e 100\%) e da água destilada. Em seguida, 25 sementes de alface foram distribuídas uniformemente nas placas, sendo acondicionadas em câmara de germinação com temperatura de $25^{\circ} \mathrm{C}$.

\section{Variáveis analisadas}

Porcentagem de germinação e a primeira contagem: foram realizadas duas contagens, a primeira e a final. $\mathrm{O}$ teste de primeira contagem baseia-se no princípio de que as amostras que apresentam maior porcentagem de plântulas normais são as mais vigorosas. No caso da alface, as contagens são realizadas aos quatro e sete dias conforme as Normas para Análise de Sementes (BRASIL, 1992).

Índice de velocidade de germinação (IVG): as avaliações das plântulas foram realizadas diariamente, a mesma hora, a partir do dia em que surgem as primeiras plântulas normais.O procedimento descrito de avaliação prossegue até o dia da última contagem. O índice de velocidade de germinação foi calculado através dos dados diários do número de plântulas normais, empregando-se a fórmula postulada por (KRZYZANOWSKI et al, 1999).

$$
\mathrm{IVG}=\frac{\mathrm{G} 1}{\mathrm{~N} 1}+\underline{\mathrm{G} 2} \ldots+\frac{\mathrm{Gn}}{\mathrm{N} 2}
$$$$
\mathrm{IVG}=\text { índice de velocidade de germinação. }
$$

\section{RESULTADOS E DISCUSSÃO}

Observou-se efeito significativo para a primeira contagem. Nas concentrações $0,50,100 \%$ de extrato aquoso de aroeira houve efeito significativo ao nível de $5 \%$ de probabilidade pelo teste de tukey para a porcentagem de germinação, primeira contagem e IVG. Em relação à interação Extrato x Concentrações houve efeito significativo apenas para a primeira contagem e o IVG.

Tabela 1 - Resumo da análise de variância das características avaliadas em alface: índice de velocidade de germinação (IVG), porcentagem de germinação (PG), primeira contagem (PC) em função das_concentrações dos extratos de aroeira fervido e não fervido.

\begin{tabular}{cccc}
\hline FV & PG & IVG & PC \\
\hline Extrato & $0,8478^{\text {ns }}$ & $0,1067^{* *}$ & $0,0175^{\text {ns }}$ \\
Tratamento & $0.000^{* *}$ & $0.000^{* *}$ & $0.0000^{* *}$ \\
Extrato xTratamento & $0,6233^{\mathrm{ns}}$ & $0,0146^{* *}$ & $0,0085^{* *}$ \\
\hline Média & 66,3429 & 12,56 & 61,16 \\
CV(\%) & 10,89 & 11,19 & 10,17
\end{tabular}

** significância ao nível de $5 \%$ de probabilidade.

A porcentagem de germinação em extrato aquoso fervido e o não fervido apresentaram diferença significativa nas três concentrações de $0,50,100 \%$. Havendo na concentração de $100 \%$ um menor taxa de germinação, onde chega a metade comparado com a concentração de $0 \%$ de extrato aquoso de aroeira (tabela 2). 
Segundo Gusman (2007) utilizando extratos aquosos de C. sylvestris evidenciaram potencialidades alelopáticas na germinação das sementes de mostarda, brócolis e couve e no crescimento das espécies testadas e com o aumento das concentrações a partir de $70 \%$ dos extratos aquosos utilizados ocorreram um aumento na redução da germinação e do crescimento nas estruturas vegetais das espécies testadas.
Em relação à primeira contagem, no extrato aquoso fervido, a concentração de 50 e $100 \%$ não apresentou diferença significativa, havendo uma melhor germinação na concentração de $0 \%$ de extrato aquoso. No extrato aquoso não fervido, as médias de todas as concentrações diferiram estatisticamente entre si

Tabela 2 - Extrato aquoso de Aroeira em diferentes concentrações, com fervido e não fervido sobre sementes de alface (Lactuta sativa).

\begin{tabular}{cccc}
\hline Tratamento & $\begin{array}{c}\text { Porcentagem de } \\
\text { Germinação }\end{array}$ & IVG & $\mathbf{1}^{\circ}$ Contagem \\
\hline Extrato fervido & $87,11 \mathrm{a}$ & $21,65 \mathrm{a}$ & $85,89 \mathrm{a}$ \\
$\mathbf{0 \%}$ & $66,02 \mathrm{~b}$ & $9,58 \mathrm{~b}$ & $39,14 \mathrm{~b}$ \\
$\mathbf{1 0 0 \%}$ & $46,75 \mathrm{c}$ & $4,99 \mathrm{c}$ & $48,50 \mathrm{~b}$ \\
\hline Extrato não fervido & & & \\
\hline $\mathbf{0 \%}$ & $83,00 \mathrm{a}$ & $21,36 \mathrm{a}$ & $81,34 \mathrm{a}$ \\
$\mathbf{1 0 0 \%}$ & $69,03 \mathrm{~b}$ & $13,23 \mathrm{~b}$ & $65,99 \mathrm{~b}$ \\
& $46,13 \mathrm{c}$ & $4,56 \mathrm{c}$ & $46,13 \mathrm{c}$
\end{tabular}

Dados de germinação transformados em arc seno $\sqrt{\mathrm{x}} / 100$. Médias seguidas pela mesma letra na coluna, não diferem estatisticamente entre si pelo teste de Tukey a $5 \%$ de probabilidade.

No IVG os valores diferiram estatisticamente em todas as concentrações nos dois tratamentos fervido e não fervido.

Observa-se que os valores do IVG vêm reforçar os valores encontrados na porcentagem de germinação em relação à alelopatia. À medida que a concentração dos extratos aumenta, ocorre uma diminuição da germinação.

De acordo Ferreira e Borghetti (2004) muitas vezes, o efeito alelopático não se dá pela germiniabilidade, mas sobre a velocidade de germinação ou sobre outro parâmetro do processo. $\mathrm{O}$ efeito alelopático pode provocar alterações na curva de distribuição da germinação ou no padrão polimodal de distribuição de germinação das sementes devido ao ruído informacional (interferências ambientais que bloqueiam ou retardam o andamento de processos metabólicos).

\section{CONCLUSÃO}

Houve uma menor porcentagem de germinação, primeira contagem e IVG de plântulas de alface na concentração de $100 \%$ do extrato aquoso de aroeira, tanto fervido como o não fervido.
O extrato aquoso de aroeira na concentração (100\%) apresentou efeito alelopático na germinação de sementes de alface.

\section{REFERENCIAS BIBLIOGRÁFICAS}

BRASIL, Ministério da Agricultura e Reforma Agrária. Regras para Análise de Sementes. BRASÍLIA: 1992. 365 p.

FERREIRA, Alfredo Gui e BORGHETTI, Fabian. Germinação: Do básico ao aplicado. Porto Alegre: Editora Artmed, 2004.

FIGUEIRA, F. A. R. Manual de olericultura: cultura e comercialização de hortaliças. 2 ed. São Paulo: Agronômica Ceres, v. 2,1982.

GUSMAN, G. S.; Bittencourt, A. H. C.; Vestena, S. AVALIAÇÃO ALELOPÁTICA DE GUAÇATONGA 
(Casearia sylvestris Sw.) NA GERMINAÇÃO E NO CRESCIMENTO DE ESPÉCIES CULTIVADAS. XXVII ENCONTRO REGIONAL DE BOTÂNICOS ERBOT. Conservação dos Ecossistemas Costeiros do Espírito Santo, 2007.

MANO, Ana Raquel de Oliveira. EFEITO ALELOPÁTICO DO EXTRATO AQUOSO DE SEMENTES DE CUMARU (Amburana cearensis S.) SOBRE A GERMINAÇÃO DE SEMENTES, DESENVOLVIMENTO E CRESCIMENTO DE PLÂNTULAS DE ALFACE, PICÃO-PRETO E CARRAPICHO. Tese de dissertação, Fortaleza - Ceará, 2006.

NESEllO, M. Á.; Pauletti, G.; Santos, A. C. A. e AttiSerafini, L. EFEITO ALELOPÁTICO DO ÓLEO ESSENCIAL DE Schinus terebinthifolius SOBRE Lactuca sativa e Bidens pilosa. A. Ciências Exatas e da Terra, Anais da 58 Reunião Anual da SBPC

SEVERINO, Liv Soares; LIMA, Rosiane de Lourdes Silva; ALBUQUERQUE, Robson César e BELTRÃO, Esberad de Macedo. ALELOPATIA DE PLANTAS DANINHAS SOBRE A MAMONEIRA. Embrapa Algodão. $2^{\circ}$ Congresso Brasileiro de Mamona.

SIGRIST, Sergio Roberto. Aroeira. Disponível em $<$ ci-67. ciagri.usp.br/pm/ver_1pl.asp?f_cod=13 - 15k> acessado no dia 20 de novembro.

SILVA, Z. L. Alelopatia e defesa em plantas. Boletim Geográfico, Rio de Janeiro, v. 36, n. 258-259, p. 90-96, 1978.

SOUZA, SÉRGIO ALESSANDRO MACHADO. Biotestes na Avaliação da Fitotoxicidade de Extratos Aquosos de Plantas Medicinais Nativas do Rio Grande do Sul. Monografia de conclusão de curso. Universidade Federal de Pelotas - RS, 2005.

KRZYZANOWSKI, Francisco Carlos; Vieira, Roberval Daiton e Neto, José de Barros França Neto. Vigor de sementes: conceitos e testes. Londrina: ABRATES, 1999. 218p. 